\title{
APOIO MATRICIAL EM SAÚDE MENTAL NO SUS DE BELO HORIZONTE: PERSPECTIVA DOS TRABALHADORES
}

\author{
THE MATRIX SUPPORT IN MENTAL HEALTH IN THE HEALTH UNIFIED \\ SYSTEM OF BELO HORIZONTE: PERSPECTIVE OF WORKERS
}

\author{
EL APOYO DE MATRIZ EN SALUD MENTAL EN EL SISTEMA ÚNICO DE SALUD \\ DE BELO HORIZONTE: PERSPECTIVA DE LOS TRABAJADORES
}

\author{
Natália Freitas Dantas ${ }^{1}$ \\ Izabel Christina Friche Passos ${ }^{2}$
}

Resumo Trata-se de pesquisa empírica com o objetivo de analisar a prática do apoio matricial em saúde mental com base no estudo de caso da experiência da cidade de Belo Horizonte, Minas Gerais, ocorrida entre os anos de 2013-2014. Mediante uma abordagem qualitativa, realizaram-se entrevistas do tipo semiestruturado e individual com cinco psicólogos e dois representantes da gestão envolvidos com o apoio matricial em saúde mental do município, além de observação-participante em reuniões de matriciamento. Os dados foram analisados segundo a metodologia da análise de conteúdo. Nas reflexões finais, percebeu-se que o apoio matricial tem transformado a relação de trabalho nas unidades básicas de saúde no sentido da corresponsabilização e do trabalho integrado entre as equipes. No entanto, ainda é preciso avançar no tocante à construção do projeto terapêutico, ampliando o escopo de intervenções além do atendimento clínico-individual, incluindo a perspectiva do trabalho com grupos e no território.

Palavras-chave saúde mental; atenção básica; apoio matricial.
Abstract This research aims to examine the practice of matrix support in mental health from the case study of the experience of the city of Belo Horizonte, Minas Gerais, Brazil, between the years 2013-2014. From a qualitative approach, there were semi-structured and individual type of interviews with five psychologists and two representatives of management involved with this in mental health in the city, as well as participant observation in matricial meetings. Data were analyzed using the methodology of content analysis. In the final reflections, it is clear that the support matrix has transformed the employment relationship in basic health units in the sense of co-responsibility and integrated work between the teams. Nevertheless, we still need to move forward with regard to the construction of the treatment plan, expanding the scope of interventions beyond the clinical and individual care, including the prospect of working with groups and in the territory. Keywords mental health; primary care; support matrix. 


\section{Introdução}

O estudo que originou este artigo teve como objetivo principal analisar a prática do apoio matricial (AM) em saúde mental mediante o estudo de caso da experiência da cidade de Belo Horizonte, em Minas Gerais. Para tanto, optou-se por privilegiar na pesquisa os psicólogos da atenção básica, especificamente os profissionais da equipe de saúde mental, por serem estes os principais responsáveis pelo AM em saúde mental na rede de saúde do município. Os gestores também foram abordados a fim de se compreender a percepção desse processo no nível gerencial. Embora a pesquisa tenha ouvido privilegiadamente os psicólogos, os resultados alcançados, validados também pela observação participante, foram abrangentes.

A criação das equipes de AM merece destaque como um momento de importantes mudanças no processo de trabalho no âmbito da atenção primária em saúde (APS), na medida em que instaura um novo modelo de trabalho que visa principalmente à atuação conjunta de diferentes profissionais e ao compartilhamento de saberes, invertendo a lógica dominante do encaminhamento de casos. A estratégia do apoio substitui o 'especialismo' profissional (D'Amour et al., 2008), que fragmenta o cuidado, pelo trabalho colaborativo entre os diversos núcleos de saber presentes nas equipes, em consonância com o princípio da integralidade preconizado pelo Sistema Único de Saúde (SUS) (Furtado, 2007).

Dimenstein e colaboradores (2009) afirmam que a saúde mental deve ser entendida como um campo de intervenção prioritário para as equipes da Estratégia Saúde da Família (ESF), pois estas têm potencialidade de atuar não só na unidade de saúde mas também no espaço social onde a comunidade vive e circula. Desse modo, estabelece vínculos de compromisso e corresponsabilidade com a população, norteados por uma perspectiva ampliada de cuidado, de modo a intervir sobre fatores de risco aos quais a comunidade está exposta - sendo os transtornos mentais um dos mais recorrentes.

De acordo com Bachetti (2013), aproximadamente $20 \%$ dos atendimentos prestados na APS estão relacionados com alguma queixa de transtornos mentais. Apenas 3\% são de transtornos severos, evidenciando a resolubilidade que a rede básica pode apresentar diante de demandas recorrentes. Campos e Gama (2008) apontam para a ausência de uma política mais efetiva para atender aos transtornos mentais menos graves. O desafio apresentado é o de construir uma rede de assistência competente, uma vez que grande parte dessa demanda relacionada à saúde mental chega diariamente na atenção básica, ${ }^{3}$ porta de entrada do sistema de saúde.

\section{A proposta do apoio matricial}

O Ministério da Saúde (Brasil, 2004) propõe a estratégia do AM - que não se restringe à saúde mental - com o intuito de organizar os fluxos, articular 
os diversos níveis de atenção e ampliar a resolubilidade da APS, o que vem solucionar em parte o problema apontado. Ao enfatizar a relevância do processo dialógico no trabalho em saúde, tanto no nível individual como no coletivo, a nova estratégia facilita a integração das práticas de cuidado em um nível ampliado de atuação (Brasil, 2005).

O termo 'matricial', de acordo com Campos e Domitti (2007), indica uma mudança radical na posição do especialista em relação ao profissional que demanda o seu apoio. Inspirado no modelo de gestão do trabalho em matriz, troca a linha de comando vertical, que induz à fragmentação dos processos de trabalho, por ações horizontais que atinjam vários desses departamentos.

Para Campos e Domitti (2007), o emprego do termo matricial indica a possibilidade de

sugerir que profissionais de referência e especialistas mantenham uma relação horizontal, e não apenas vertical como recomenda a tradição dos sistemas de saúde. Trata-se de uma tentativa de atenuar a rigidez dos sistemas de saúde quando planejados de maneira muito estrita segundo as diretrizes clássicas de hierarquização e regionalização (Campos e Domitti, 2007, p. 402).

Acerca da equipe de referência, Campos (1998) preconiza que não deveria haver, quer em modalidade ambulatorial, quer na de internação, nenhum paciente sem um profissional escolhido ou designado para ser sua referência. Desse modo, "cada técnico ou cada miniequipe teriam responsabilidade integral sobre determinado número de casos" (Campos, 1998, p. 868). Os demais trabalhadores os apoiariam mediante ações articuladas em movimentos matriciais: interconsultas, discussão de casos, entre outros.

Segundo Campos e Cunha (2011), equipe de referência é a menor unidade de poder em uma organização. Para os referidos autores, Apoio Matricial e Equipe de Referência são “arranjos organizacionais e metodologia para a gestão do trabalho em saúde, objetivando ampliar as possibilidades de realizar-se clínica ampliada e integração dialógica entre distintas especialidades e profissões" (Campos e Cunha, 2011, p. 965)

Campos (1999) reforça a ideia de que a principal função do profissional de referência é elaborar e aplicar o projeto terapêutico singular (PTS), que “implica determinado diagnóstico, depende de uma aproximação entre cliente, família e profissionais de referência, e implica na instituição de práticas individuais, de grupo ou mais coletivas" (Campos, 1999, p. 397).

Oliveira (2008) define o PTS como "um movimento de coprodução e de cogestão do processo terapêutico de indivíduos ou coletivos, em situação de vulnerabilidade" (Oliveira, 2008, p. 275), sendo um dos recursos utilizados pelo AM nos momentos de discussão de casos entre os profissionais. Trata-se da proposição de projetos singulares, construídos conjuntamente com o usu- 
ário e a família, que levem em conta não só o sujeito, mas sua interação com o meio, com as questões sociais, políticas e culturais.

Dimenstein e colaboradores (2009) acreditam que a reforma psiquiátrica não pode avançar nos seus inovadores propósitos se a atenção à saúde mental se restringir aos serviços especializados, não bastando se empenhar na rede substitutiva, mas devendo, isto sim, compreender o cuidado em saúde mental envolvendo todos os níveis de assistência da rede de saúde. Este apontamento é reforçado pela portaria n. 3.088/2011, que institui a Rede de Atenção Psicossocial (RAPS), na medida em que apresenta como objetivo: “Garantir a articulação e integração dos pontos de atenção das redes de saúde no território, qualificando o cuidado por meio do acolhimento, do acompanhamento contínuo e da atenção às urgências" (Brasil, 2011b, p. 3). A rede está constituída por serviços de atenção básica em saúde, atenção psicossocial especializada, atenção de urgência e emergência, atenção residencial de caráter transitório, atenção hospitalar, estratégias de desinstitucionalização e reabilitação psicossocial.

Uma consequência importante do apoio matricial é que ele tenta reverter a lógica do encaminhamento, que pressupõe a hierarquização entre os saberes e a transferência de responsabilidades, para propor a lógica da corresponsabilização, que substitui a relação poder/saber pelo compartilhar de responsabilidades, ao exigir que os profissionais decidam juntos sobre o andamento de cada caso, bem como sobre seu acompanhamento. A respeito disso, Figueiredo e Campos (2009) ressaltam que

o apoio matricial seria uma ferramenta para agenciar a indispensável instrumentalização das equipes na ampliação da clínica, subvertendo o modelo médico dominante, que se traduz na fragmentação do trabalho e na produção excessiva de encaminhamentos, muitas vezes desnecessários, às diversas especialidades (Figueiredo e Campos, 2009, p. 130).

O Ministério da Saúde (Brasil, 2004) reforça a ideia de corresponsabilização pelos casos e acrescenta que quando o território tiver uma grande população de abrangência, "é importante que o CAPS discuta com o gestor local a possibilidade de acrescentar (...) uma ou mais equipes de saúde mental, destinadas a realizar essas atividades de apoio à rede básica" (Brasil, 2004, p. 25).

A fim de efetivar a estratégia do AM, o Ministério da Saúde (Brasil, 2004) instituiu o Núcleo de Apoio à Saúde da Família (Nasf) como responsável pelo apoio à ESF, de modo a dar suporte e fortalecê-la no exercício do cuidado integral em saúde. A portaria n. 2.488/2011 (Brasil, 201 la) esclarece que o referido núcleo deve atuar na perspectiva do AM (Brasil, 2009), constituindo-se em retaguarda especializada para as equipes de saúde da família, desenvolvendo trabalho compartilhado e colaborativo nas dimensões clínico-assistencial e técnico-pedagógica. 
Em relação à saúde mental, preconiza-se que o Nasf deve atuar conjuntamente com outras equipes especializadas, como o Centro de Atenção Psicossocial (Caps), no sentido da corresponsabilização pelos casos, para facilitar a integração com as equipes de saúde da família. Esse arranjo institucional visa promover uma articulação entre as unidades locais de saúde e os serviços de saúde mental especializados, de modo a organizar o fluxo e o processo de trabalho, podendo o Nasf atuar como mediador dessa integração (Brasil, 2014). No caso específico de Belo Horizonte, as equipes de saúde mental (ESMs) assumiram essa responsabilidade, como se mostrará em seguida.

\section{Conhecendo a rede de saúde mental de Belo Horizonte}

O objeto de estudo foi a rede de serviços de saúde da cidade de Belo Horizonte, escolhida pelos avanços alcançados nos processos da reforma psiquiátrica e por seu reconhecido histórico de articulação entre atenção básica e saúde mental, fomentado pelo AM (Minas Gerais, 2006).

Na organização do sistema de saúde do município, a saúde mental na atenção primária é apoiada pelas ESMs e não pelo Nasf, como preconiza a diretriz nacional. Tais equipes foram criadas nos anos 1980 com o objetivo de atender à demanda de saúde mental na atenção básica por meio da produção de um padrão de atendimento mais participativo e capaz de abranger os níveis primário e secundário de assistência, descentralizando o cuidado em saúde mental com o deslocamento do eixo de atendimento do hospital e da rede terciária para as unidades básicas de saúde (Goulart, 1993).

As ESMs funcionam na perspectiva do AM, não sendo porta de entrada para os serviços de saúde, pois atuam de forma compartilhada ao dar suporte às equipes de saúde da família (Ferreira-Neto, 2011). A equipe é formada por psicólogo, psiquiatra e assistente social, responsáveis por apoiar matricialmente as equipes de saúde da família no tocante às questões da saúde mental. Vale destacar que dessa equipe apenas o psicólogo é profissional fixo e exclusivo, uma vez que o psiquiatra atende à demanda de mais de uma unidade básica e o assistente social não é exclusivo da equipe de saúde mental, atendendo a outras demandas sociais da unidade básica de saúde como um todo.

O público prioritário de atendimento das ESMs são os pacientes com transtornos mentais graves e persistentes, bem como os egressos de internações psiquiátricas (Goulart, 1993; Ferreira-Neto, 2011).

Atualmente, Belo Horizonte tem 148 unidades básicas de saúde (UBSs), distribuídas entre nove distritos regionais de saúde. Cada uma delas conta com uma equipe de saúde mental, que por sua vez tem um psicólogo atuando diretamente no apoio matricial às equipes de saúde da família (Belo Horizonte, 2013). 


\section{O caminhar da pesquisa}

A pesquisa aqui apresentada resultou de dissertação de mestrado realizada no período de 2012 a 2014, tendo caráter qualitativo (Minayo, 2010) e cunho exploratório (Chizzotti, 2011). Foram utilizadas como técnicas entrevistas semiestruturadas individuais feitas com cinco psicólogos da equipe de saúde mental e dois representantes da gestão da atenção básica, além de observação-participante realizada durante três reuniões de matriciamento. O campo escolhido foram quatro UBSs da cidade de Belo Horizonte: três da Regional Nordeste e uma da Regional Noroeste, de acordo com indicação feita pela Coordenação de Saúde Mental do município, com a justificativa de que as referidas UBSs tinham o AM mais estruturado no cotidiano das equipes.

Todas as entrevistas foram gravadas, posteriormente transcritas, e as questões que as nortearam tiveram o objetivo de conhecer o trabalho do AM por meio da exploração das seguintes dimensões: compreensão do AM; rotina de trabalho do apoiador; integração com as equipes de saúde da família; organização do processo de trabalho do AM; principais desafios para o trabalho do apoiador.

A observação-participante (May, 2004) foi realizada em três reuniões de matriciamento ocorridas cada uma em uma UBS, com o intuito de perceber os assuntos tratados e a integração dos profissionais no contexto das reuniões. Para registro das observações, foram feitas anotações em diário de campo pela pesquisadora, com consentimento dos presentes. Para análise dos dados, utilizou-se como referência a análise de conteúdo - que, de acordo com Bardin (1995), é um método de investigação compreendido como um conjunto de técnicas de análise das comunicações que emprega procedimentos sistemáticos e objetivos de descrição do conteúdo das mensagens, com a intenção de fazer inferência de conhecimentos relativos às condições de produção.

A pesquisa foi realizada com o consentimento de todos os envolvidos no processo, incluindo gerentes das unidades básicas, profissionais pesquisados, gerentes regionais, bem como a equipe da coordenação de saúde mental envolvida no trabalho, tanto para a realização das entrevistas quanto para a observação-participante das reuniões de matriciamento. Os entrevistados assinaram o termo de consentimento livre e esclarecido, de modo a permitir a realização das entrevistas.

A pesquisa foi desenvolvida conforme a resolução n. 466/12 do Conselho Nacional de Saúde (Brasil, 2012), tendo sido aprovada pelo Comitê de Ética em Pesquisa da Universidade Federal de Minas Gerais. Todos os participantes assinaram o termo de consentimento livre e esclarecido. Não houve fonte de financiamento para a pesquisa e não existiram conflitos de interesse. 


\section{O fazer do apoio matricial na atenção primária de Belo Horizonte}

As categorias de análise encontradas corresponderam aos principais aspectos descritivos do matriciamento em saúde mental de Belo Horizonte, construídas com base nos dados coletados nas entrevistas e nas observações-participantes. São elas: apoio matricial compreendido a partir das reuniões de matriciamento; rotina de trabalho do apoiador; relação entre ESM e Nasf; e desafios para o AM.

\section{Apoio matricial compreendido a partir das reuniões de matriciamento}

As reuniões de matriciamento acontecem em todas as UBSs, envolvendo os profissionais da ESF e da ESM, e têm o papel de organizar o trabalho das ESMs, definindo o fluxo para os casos compartilhados com a saúde da família. Segundo os próprios entrevistados, essas reuniões organizam todo o processo do AM, ao ordenar o trabalho realizado.

O primeiro passo é o matriciamento, a não ser o caso que não possa aguardar, porque a reunião geralmente é uma vez ao mês, reunião de AM. (...) É como se a reunião de matriciamento direcionasse as atividades dali pra frente (Gestor/a entrevistado/a 1).

Essa reunião de matriciamento já tem uma organização de acontecer uma vez por mês com os profissionais de saúde da família. Quem participa? O médico de saúde da família, o enfermeiro, os agentes comunitários participam (Gestor/a entrevistado/a 2).

As referidas reuniões costumam acontecer mensalmente em cada equipe de saúde da família, devendo contar com a participação dos profissionais envolvidos. A equipe de saúde da família leva os casos relacionados à saúde mental para - juntamente com a ESM - serem traçadas as intervenções necessárias para cada situação.

O objetivo da reunião de matriciamento é discutir casos e estabelecer o projeto terapêutico do usuário, família ou comunidade em corresponsabilização entre ESM e saúde da família.

São reuniões de discussão de casos, e em cima dessas discussões vão sendo construídos projetos terapêuticos ou às vezes não é um caso da saúde mental e a equipe ajuda a discutir, pensar que outras alternativas possam ter para aquele caso, tanto ações que a própria equipe de SF possa desenvolver como ações para fora do PSF (Gestor/a entrevistado/a 1).

Alguns psicólogos entrevistados contaram que nessas reuniões também há momentos pedagógicos, de discussão sobre temas referentes à saúde mental, bem como decorrentes de casos discutidos. Disseram ainda que esse tipo de atividade tem contribuído para a melhor compreensão do que sejam os casos trazidos pela equipe, especialmente pelo agente comunitário de saúde (ACS). 
Mas, ao mesmo tempo, a gente também tem discussão de conceitos teóricos que às vezes demanda. Por exemplo, a questão do álcool e drogas... E aí a partir disso a gente faz outros tipos de trabalho com eles. Eu já passei filme para discussão, nós já fizemos roda de conversa com a rede, enfim... A partir de um caso ou uma demanda em função de alguma questão de uma equipe ou de um profissional, a gente também trabalha dentro do matriciamento (Psicólogo/a entrevistado/a 2).

É interessante abordar o conceito de AM trazido por Campos e Domitti (2007), quando argumentam que "o AM pretende oferecer tanto retaguarda assistencial quanto suporte técnico-pedagógico às equipes de referência" (Campos e Domitti, 2007, p. 400). Os autores elucidam que um dos papéis do AM é o suporte pedagógico no sentido de capacitar as equipes de saúde da família para compreender as características da saúde mental e lidar melhor com essas questões quando aparecem no acolhimento.

Acerca disto, é interessante perceber como a questão da lógica do suporte pedagógico também é percebida em outros estudos. Fittipaldi, Romano e Barros (2015) relatam que a educação permanente foi pontuada como relevante para o trabalho com o apoio matricial, na medida em que potencializa a qualificação das práticas em saúde e de reorganização do processo de trabalho. Barros e colaboradores (2015) também apontam para essa temática quando ressaltam que

além das discussões de caso e dos atendimentos compartilhados, o chamado 'apoio técnico-pedagógico' ou 'apoio educativo', que compõe o matriciamento, acontecia em todas as ações desenvolvidas pela parceria estabelecida com EqSF (Barros et al., 2015, p. 2.852).

Os entrevistados enfatizaram o matriciamento como importante também no processo de desmistificação do doente mental dentro da UBS, junto às equipes de saúde da família. Essa conduta diminuía o distanciamento entre os profissionais da atenção primária e a saúde mental e melhorava o acolhimento necessário.

(...) ele também traz essa desmistificação, elas começam a conhecer mais. Muitas vezes, na percepção [da equipe], “ah, o paciente é inadequado, ele tá delirando, ele é isso", então começam a conhecer o que é isso. Paciente tá com comportamento inadequado, ele tá alucinando, tá delirando, como é que é isso? A equipe começa também a conhecer o que é isso e vai se aproximando mais desse paciente, vai desmistificando isso, de que ele é perigoso, de que "ah, isso é coisa da saúde mental" (Psicólogo/a entrevistado/a 5).

Souza e Tófoli (2012) apontam para a dificuldade que as equipes apresentam em lidar com os usuários da saúde mental, o que se reflete na grande 
quantidade de encaminhamentos atrelada a um relativo desconhecimento dos casos, frequentemente expresso nas dificuldades de identificação e acompanhamento das pessoas com transtorno mental.

$\mathrm{Na}$ observação das reuniões de matriciamento, percebeu-se participação maciça dos ACSs e participação variada entre enfermeiros e médicos das equipes. As reuniões tinham duração média de uma hora e meia a duas horas, em que se discutiam entre 12 e 15 casos. Nas três reuniões observadas, percebeu-se uma predominância do atendimento individual, como projeto terapêutico, para a maioria dos casos de saúde mental e pouca ou nenhuma intervenção grupal e coletiva.

O psicólogo ainda é o principal articulador da reunião de matriciamento. Tal afirmativa pode ser justificada na medida em que ele é o único membro exclusivo da equipe, uma vez que o psiquiatra está responsável por mais de um centro de saúde, tendo, pois, carga horária reduzida na unidade, e o assistente social é responsável por todas as questões sociais inerentes ao cotidiano da UBS.

Devido à grande demanda, os casos eram discutidos de forma superficial, restringindo-se, em sua maioria, ao encaminhamento dos casos da equipe de saúde da família para a ESM. Apesar disso, percebeu-se que as reuniões eram espaços potentes de trabalho compartilhado entre ESM e equipe de saúde da família, ou seja, eram momentos de encontro entre as equipes, sedimentando-se nas agendas dos profissionais e refletindo o suporte necessário para o acompanhamento dos casos da saúde mental.

\section{Rotina de trabalho do apoiador}

Percebeu-se na fala dos entrevistados que a reunião de matriciamento era organizadora da rotina de trabalho do psicólogo, uma vez que a maioria dos casos acompanhados vinha de discussões e projetos terapêuticos estabelecidos nesses encontros. A conduta terapêutica mais apontada pelos psicólogos referia-se aos atendimentos ambulatoriais. Em geral, os profissionais disseram que estavam sempre com a agenda cheia de atendimentos, limitando, muitas vezes, seu campo de atuação - o que representa uma contradição, pois o objetivo do AM é diversificar as formas de cuidado em saúde no sentido da ampliação da clínica e das propostas terapêuticas.

É... Muitos atendimentos, né, muitos. Aqui tem uma demanda considerável, né, aqui durante o dia a dia o arroz com feijão é o atendimento mesmo. É uma agenda que se você não segurar... (Psicólogo/a entrevistado/a 3).

Lima e Dimenstein (2016) também apontam para essa fragilidade quando destacam em pesquisa realizada que o serviço especializado estudado se habituou 
a ser um serviço predial, quase como um ambulatório. “Começamos a nos trancar dentro dos portões e esquecer que lá fora existe um território vivo, pulsando, de onde vêm as pessoas que nos procuram" (Lima e Dimenstein, 2016, p. 629).

Diante disso, é importante frisar que "o cuidado compartilhado prevê uma rede de ações, dispositivos de saúde e dispositivos comunitários que possibilitem que o processo de cuidar se organize tendo como eixo central o sujeito e seu processo de saúde/doença" (Brasil, 2009, p. 36). Logo, quando o escopo de atuação se limita muito ao âmbito individual, deixando as intervenções comunitárias de lado, diminui a resolutividade da equipe, assim como a potência de trabalho na APS.

\section{Fluxo de atendimentos}

Com base nas entrevistas, perceberam-se alguns fluxos para os atendimentos com o psicólogo, que apresentamos de forma esquemática no Diagrama 1.

\section{Diagrama 1}

Fluxo para atendimento do psicólogo

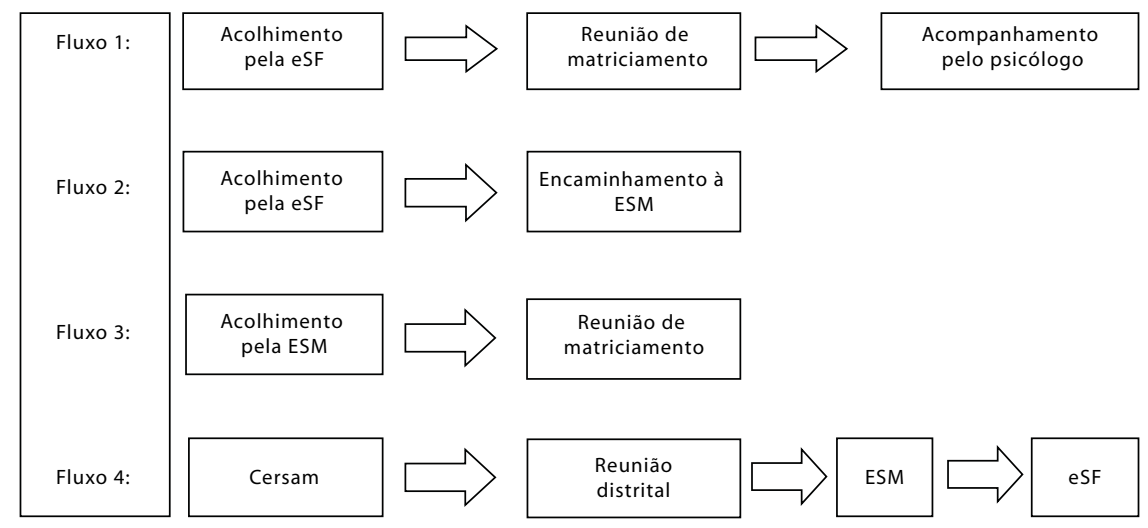

Fonte: As autoras.

Nota: eSF - Equipe de saúde da família.

O primeiro fluxo é via ESF. Por meio dele, os usuários passam pelo acolhimento na equipe de saúde da família, que avalia a necessidade de levar o caso para a reunião de matriciamento. Nessa reunião, o psicólogo analisa a relevância de realizar o acompanhamento.

O segundo fluxo é para os casos considerados graves que chegam à unidade e não podem esperar pelo dia da reunião do matriciamento. Os casos graves que têm acesso direto à ESM são os neuróticos e psicóticos, ou usuários de álcool e outras drogas, encaminhados pelo Centro de Referência em Saúde Mental (Cersam) ${ }^{4}$ e também os usuários que cometeram tentativa de autoextermínio. Desse modo, tais usuários são acolhidos pela equipe de saúde da 
família e encaminhados diretamente para a equipe de saúde da família, sem precisar esperar pela reunião de matriciamento. É o repasse direto.

O terceiro fluxo é quando o psicólogo, ou psiquiatra, é acionado diretamente para acolher o caso e estabelecer o atendimento. Nesse caso, o fluxo é invertido, pois o usuário chega direto para a ESM, sem passar inicialmente pelo acolhimento na equipe de saúde da família, e só em seguida será discutido na reunião de matriciamento, quando passará a ser acompanhado pela saúde da família. Quando isso acontece, o psicólogo sai do papel de apoiador para assumir diretamente a responsabilidade na condução do caso, mesmo que seja em caráter provisório, invertendo a lógica do AM. Esses casos acontecem, em geral, quando a ESM já conhece o usuário por ter acompanhado o caso em momento anterior.

O último e quarto fluxo ocorre quando os casos são encaminhados pelo Cersam diretamente para a ESM, via reunião distrital que acontece periodicamente e reúne os profissionais dos Cersams, ESM e saúde da família, embora estes últimos em menor número. Nessas reuniões, alguns casos são levados tanto pelas ESMs quanto pelos profissionais do Cersam a fim de discuti-los entre si, seja no sentido do encaminhamento, seja no da corresponsabilização pelo cuidado entre nível básico e especializado.

Alguns entrevistados mencionaram que os casos acompanhados pela ESM deveriam estar sempre vinculados à equipe de saúde da família, uma vez que o usuário nunca deixa de ser referenciado pela saúde da família, sendo a ESM responsável pelo apoio e suporte em situações específicas de atendimento.

Então assim, se a pessoa tem diabetes, tem hipertensão e tem transtorno mental, é da equipe, né? Se o usuário vai precisar de uma atenção específica da saúde mental, aí é outra história. Precisa do psiquiatra acompanhar pessoalmente aquela pessoa? Ele vai especificamente fazer uma avaliação daquela pessoa e fazer uma prescrição e depois reencaminhar pro saúde da família (Psicólogo/a entrevistado/a 4).

Nesse ponto, Campos (1999) afirma que quando um paciente se utiliza de um serviço de apoio, ele nunca deixa de estar atrelado à equipe de referência. Assim, não há encaminhamento, mas desenho de projetos terapêuticos executados por um conjunto mais amplo de trabalhadores. No entanto, a responsabilidade principal pela condução do caso continua com a equipe de referência.

Com base no exposto, percebe-se que os fluxos servem para dar um direcionamento ao processo de trabalho, mas nota-se também que eles são reinventados no cotidiano dos serviços para dar conta das diversas demandas que surgem nas UBSs. Apesar da diversidade de opções, de uma forma ou de outra, o fluxo sempre passa pela equipe de saúde da família, o que reflete uma postura matricial, apesar de ainda estar centrada nos atendimentos individuais.

Souza e Tófoli (2012) apontam em seu estudo as fragilidades no estabelecimento de fluxos, bem como a falta de estrutura comunicativa dos sistemas 
de referência e contrarreferência, o que leva ao desconhecimento e à burocratização das formas de encaminhamento para o nível de atenção secundária.

Além dos atendimentos, responsáveis por grande parte da rotina dos profissionais, dois entrevistados mencionaram intervenções grupais como parte de sua rotina, em geral grupo de mulheres. Entretanto, a relevância dessas ações na rotina de trabalho da ESM pareceu muito pequena e inexpressiva. Fittipaldi, Romano e Barros (2015) ressaltam que, além das consultas, as demais ações do processo de trabalho do apoio matricial parecem ser pouco utilizadas pelas equipes, ou pouco compreendidas em seu potencial e metodologia.

Também se mencionou o envolvimento em atividades gerais da UBS, em razão da demanda da gerência, para facilitar a organização do trabalho na unidade como um todo.

Então existe aqui no centro de saúde um como se fosse um matriciamento geral do centro de saúde, com a participação de um grande número de funcionários, e a gerente demandou a minha participação, a participação da assistente social. Não é especificamente [saúde mental], mas aí a gente vai tentando junto algumas abordagens para esse outro público (Psicólogo/a entrevistado/a 1).

Além dessas atividades, alguns psicólogos referiram a participação em reuniões das equipes de saúde da família, bem como em reuniões distritais que promoviam o encontro entre os profissionais de todas as UBSs da regional de saúde a que pertenciam e a discussão de casos com outros equipamentos da rede de saúde. Fizeram também referência à participação em visitas domiciliares junto com o agente comunitário de saúde, a fim de prestar atendimento a usuários da saúde mental que não conseguiam chegar à UBS.

Apenas um(a) psicólogo(a) entrevistado(a) mencionou de forma breve alguns momentos em que realizou atendimento compartilhado com outros profissionais da equipe de saúde da família.

Tem o dia a dia que a gente é abordado, pode discutir caso, a gente tem atendimentos compartilhados. Já fiz vários atendimentos compartilhados com médico, enfermeiro, às vezes com ACS, auxiliar de enfermagem (Psicólogo/a entrevistado/a 2).

Fittipaldi, Romano e Barros (2015) ressaltam a dificuldade para mudança na "lógica do encaminhamento para o compartilhamento das ações, principalmente através das consultas conjuntas, uma vez que os profissionais já estão habituados a encaminhar os usuários para o agendamento individual" (Fittipaldi, Romano e Barros, 2015, p. 84).

Diante da rotina de trabalho apresentada, percebeu-se a relevância dos atendimentos individuais, ocupando a maior parte da agenda dos profissionais, que acabavam ficando com suas atividades limitadas. Talvez em decorrência disso, foi 
notável o pouco investimento em intervenções grupais, como grupos terapêuticos/comunitários, e as atividades fora do consultório, como visitas domiciliares e atendimentos conjuntos, que apareceram mencionados com menor destaque.

\section{Relação entre ESM e Nasf}

Embora não seja possível explorá-la cabalmente neste artigo, uma questão importante e complexa emergiu na pesquisa e referiu-se à interação entre ESM e Nasf. Como visto anteriormente, o Nasf é a instância criada pela Política Nacional de Saúde para trabalhar no apoio às equipes de saúde da família, e suas equipes estão alocadas nas UBSs, são multidisciplinares e algumas contam com a presença de psicólogo. É preciso recorrer ao processo histórico, ainda que muito rapidamente, para se compreender a relação particular entre as ESMs e os Nasfs no município estudado.

Em Belo Horizonte, o Nasf integrou a política de reabilitação no SUS-BH, que enfatiza ações de promoção da saúde, reabilitação e inclusão social. Segundo Azevedo (2011), os Nasfs foram inicialmente identificados como Núcleos de Apoio à Saúde da Família-Reabilitação (Nasf-R), com o objetivo principal de fornecer suporte às equipes de saúde da família no que diz respeito às ações de reabilitação.

Azevedo (2011) conta que a Secretaria Municipal de Saúde criou, em 2005, os Núcleos de Apoio à Reabilitação (NARs) com o objetivo de implantar ações de reabilitação na atenção primária, possibilitando o acesso da população a intervenções preventivas, promotoras e reabilitadoras. Com a criação do Nasf (Brasil, 2008), por meio da portaria interministerial n. 154, a Secretaria Municipal de Saúde de Belo Horizonte identificou semelhanças no trabalho desenvolvido pelo NAR e pelo Nasf e decidiu ampliar, por meio da proposta do Nasf, a experiência do NAR para todo o município e integrar as ações de promoção à saúde e assistência farmacêutica (Azevedo, 2011).

O objetivo geral do Nasf no sistema de saúde de Belo Horizonte era a implementação de ações de promoção à saúde, prevenção de doenças e reabilitação na atenção primária, a fim de ampliar a resolubilidade e a abrangência das ações, mantendo ou melhorando as condições de saúde da população. Atualmente, todas as UBSs contam com equipes de Nasf, tendo composição variada dos profissionais.

Segundo os entrevistados, a relação entre as duas equipes mostrava-se muito frágil, cada uma desenvolvendo o seu trabalho e cuidando das suas demandas isoladamente. A ESF acabava tornando-se o elo entre as referidas equipes, uma vez que ambas trabalhavam na perspectiva do apoio à ESF. Existia a compreensão da necessidade de integração, mas não havia ação nesse sentido.

Tá bem frágil, bem, bem, bem... Nós fizemos um movimento no início da gente marcar uma reunião de tempos em tempos. E aí justamente com o Nasf pra gente 
discutir alguns casos, mas aí não foi possível, pelas demandas, pelas agendas. $\mathrm{O}$ Nasf tem uma demanda maior porque responde por vários centros de saúde. Então não foi possível continuar com esse modelo. Então a equipe de saúde da família acaba sendo o elo. Então eu acho que não é bom, não. Tinha que ter uma integração maior (Psicólogo/a entrevistado/a 1).

Em relação ao trabalho entre o psicólogo da ESM e o do Nasf, percebeu-se uma lacuna ainda maior, talvez pela dificuldade de se delimitar a demanda referente a cada uma das equipes ou por essas demandas se misturarem um pouco no cotidiano de trabalho.

No caso do psicólogo fica mais difícil, mas o que eu conseguiria caracterizar a diferença é que o psicólogo da equipe de saúde mental tem as diretrizes muito bem definidas do que é o seu público a ser priorizado, que são mesmo os psicóticos, neuróticos graves, vítimas de violências. E o Nasf faria atendimentos mais pontuais, casos que poderiam ser resolvidos com uma terapia breve, mais focal, mais pontual, e outros dependendo de acompanhamento mais demorado ele vai estar encaminhando pras clínicas de reabilitação (Gestor/a entrevistado/a 1).

Em relação à demanda de trabalho desses profissionais, os entrevistados mencionaram que o público da ESM eram os neuróticos e os psicóticos graves, bem como os casos de violência e uso de drogas. Já o psicólogo do Nasf estaria mais voltado para os casos 'leves', abordados de forma pontual, sem a incidência de acompanhamento prolongado. Além disso, relatou-se que o psicólogo do Nasf estava mais voltado para questões coletivas como o trabalho com grupos, seja por faixas etárias, seja por problemáticas sociais, o que tirava um pouco o foco dos atendimentos individuais; já o psicólogo da ESM estaria mais voltado para as questões clínicas.

Havia, portanto, uma divisão tácita de tarefas, mas percebeu-se que ainda havia uma tensão entre o trabalho desses dois profissionais. Nas falas dos psicólogos da ESM, houve a percepção de que eles tinham o seu público bem definido e que o psicólogo do Nasf ainda esbarrava nessa indefinição de qual seria o seu público em termos de atenção à saúde mental. Não tivemos condições de aprofundar uma análise sobre essa questão, que demandaria envolver como sujeitos da pesquisa os profissionais do Nasf, o que não foi feito. Malgrado essa limitação, pôde-se perceber claramente um certo distanciamento entre as duas equipes, mesmo estando o trabalho de ambas atrelado diretamente à equipe de saúde da família. Uma hipótese que pode ser levantada é que como as ESMs já existiam desde a década de 1980, antes mesmo da criação do SUS, e muito antes ainda da política que criou o Nasf, elas se apropriaram da demanda dos usuários graves da saúde mental, o que aponta para uma escolha política da saúde mental de Belo Horizonte. 
Quando os Nasfs foram criados, a saúde mental na atenção básica já estava bastante 'coberta', não havendo espaço para essas novas equipes. Tem de se levar em conta que em 2013 as ESMs foram multiplicadas, sendo ampliadas de 58 para 148 equipes, de acordo com dados do Relatório de Gestão do SUS-BH (Belo Horizonte, 2013), numa clara demonstração de reforço dessas equipes pela coordenação de SM da Secretaria de Saúde.

Os tensionamentos acerca dessa questão eram evidentes e decorriam de disputas de espaço institucional e político sobre o campo de atuação da saúde mental, revelando certa fragmentação do cuidado e distanciamento da proposta nacional de integração. No Brasil, há uma histórica separação entre deficiência física e mental e o sofrimento mental; os NARs, que em Belo Horizonte deram sustentação aos Nasfs, cuidavam das primeiras.

\section{Desafios do apoio matricial}

O primeiro desafio que o AM encontra na perspectiva dos entrevistados é a abordagem aos casos ditos 'leves', que constituem a grande demanda dos usuários que procuram as UBSs e não conseguem ter a sua demanda atendida, já que não estão no perfil dos casos prioritários para atendimento.

O desafio eu fico vendo que é realmente aquela velha história daqueles casos chamados 'leves', que é uma demanda muito grande. O sofrimento da vida, essas coisas que traz [ $[\mathrm{ic}]$ um sofrimento. Então ainda tem uma tendência a demandar alguns casos que não seriam os prioritários (Psicólogo/a entrevistado/a 1).

Outra questão trazida pelos entrevistados foi a tendência de que muitas reuniões de matriciamento viessem a se tornar momentos para simples encaminhamento de casos, 'passação de casos', 'agendamentos'. Essa percepção foi muito pertinente, uma vez que nas reuniões de matriciamento observou-se de fato uma grande demanda por marcação de atendimentos, seja pelo psicólogo, seja pelo psiquiatra, invertendo, pois, a lógica da corresponsabilização trazida pela proposta do AM.

Eu acho que até hoje passa caso, é uma 'passação', muitos lugares assim, a gente cai nesse engodo o tempo inteiro. Assim, se a gente bobear aqui vai chegar uma hora que a gente vai tá [sic] só passando caso, marcando na agenda, entendeu? E aí fala que tá fazendo matriciamento, mas na verdade não tá, né? (Psicólogo/a entrevistado/a 3).

Nesse sentido, foi dito também que o AM era relevante por retirar os profissionais do saber 'psi' da referência dos casos de saúde mental. Assim, psicólogo e psiquiatra cederiam lugar para que as equipes de saúde da família assumissem a referência dos casos e acionassem o apoio em caso de necessidade. 
Tratava-se de uma mudança de paradigma em relação ao papel do psicólogo nesse processo, que agora estava sendo convidado a discutir, dividir saberes, compartilhar experiências e se mostrar mais para o grupo. E esse novo papel nem sempre era bem recebido entre todos os profissionais, havendo, em alguns momentos, resistência à implantação do modelo do apoio.

Acerca dessa questão, Campos e Domitti (2007) argumentam que o AM é um importante dispositivo para que se alcance a ampliação da clínica, por meio de uma perspectiva interdisciplinar. Pressupõem ainda algum grau de adesão a um paradigma que pense o processo saúde, doença e intervenção de modo mais complexo e dinâmico.

A rotatividade dos profissionais, em particular dos médicos, também foi abordada como desafio, pois deixava as equipes incompletas, gerava sobrecarga de trabalho; e quando entravam novos profissionais, era necessário reiniciar todo o trabalho, desde a sensibilização até à adesão efetiva deles.

Percebeu-se, ainda, a dificuldade das equipes em organizarem suas agendas de reuniões, investirem no matriciamento e se disporem para o trabalho conjunto. Em algumas unidades, o matriciamento não era priorizado, seja pelo gerente que não queria liberar a agenda dos profissionais para reuniões, seja pela equipe de saúde da família que não estava sensibilizada com a área da saúde mental, seja pelo próprio profissional que não queria abrir mão do trabalho isolado no consultório.

Compreender esses desafios é necessário ao desenvolvimento do AM, pois eles apontam para as mudanças necessárias ao aprimoramento do trabalho.

\section{Considerações finais}

Com base nos dados coletados, percebeu-se que o AM realizado no município estudado se organizava em torno da reunião de matriciamento, em que se reuniam ESM e ESF, a fim de discutir casos relacionados com a saúde mental e, a partir daí, construir o projeto terapêutico. A implantação dessa reunião foi percebida como potente por propiciar momento de encontro entre as duas equipes, facilitando a integração. No entanto, ficou evidente que esse espaço ainda era muito utilizado para 'passar casos' e pouco para a construção de projetos terapêuticos conjuntos.

O AM tem como característica o trabalho colaborativo em equipes interdisciplinares. Nesse sentido, os projetos terapêuticos devem ser construídos em conjunto, pois promovem uma relação dialógica e espaços coletivos para comunicação ativa e compartilhamento de conhecimentos entre profissionais de referência e apoiadores.

Acerca da construção compartilhada de propostas terapêuticas, o que se percebeu, no entanto, foi que os PTSs ainda estão muito centrados em atendimentos clínico-individuais por parte do psicólogo e do psiquiatra, ficando as intervenções comunitárias, grupais ou coletivas pouco desenvolvidas. 
Com relação à constituição da ESM, percebeu-se que esta ficava muitas vezes restrita apenas ao psicólogo, que tinha a responsabilidade de conduzir todas as demandas e propostas relacionadas à saúde mental da UBS. Uma reflexão que pode ser feita é sobre a pertinência de se abrirem essas equipes para a participação de outros profissionais, além do psicólogo e psiquiatra, potencializando o trabalho com outras áreas, de modo a expandir as ações além do atendimento individual priorizado pelas equipes.

Sobre a articulação entre o trabalho da ESM e o Nasf, percebeu-se que a relação, em geral, era frágil, sem momentos de interlocução entre os profissionais dessas equipes. No tocante ao papel do psicólogo, notou-se que, em razão de a demanda direcionada à ESM estar bem mais delimitada, o papel desse profissional aparecia mais definido que o do psicólogo do Nasf, ainda em processo de construção. Verificaram-se algumas tensões entre as equipes não analisadas em profundidade por nosso estudo, por extrapolar o objetivo da pesquisa e demandar, necessariamente, uma ampliação de seu escopo.

Entre os principais desafios para o trabalho em AM, encontra-se a sua integração com a equipe de saúde da família, principalmente na sensibilização para o trabalho com a saúde mental, a fim de superar o isolamento decorrente de um modelo de prática de consultório ainda dominante nas ESMs, visando a um trabalho efetivamente integrado à atenção primária.

Apesar das tensões e dos desafios apresentados, o AM foi percebido como uma estratégia potente para o trabalho em saúde mental na atenção primária, que tem contribuído para transformar a relação de trabalho nas UBSs no sentido da corresponsabilização e do trabalho integrado entre as equipes.

A perspectiva do apoio vem incrementar a interdisciplinaridade da atenção, ao estabelecer como meta a corresponsabilização das equipes pelos usuários, tornando as relações de cuidado horizontais. Entretanto, vários aspectos precisam avançar para que o AM aconteça de forma mais efetiva e sólida, especialmente no tocante à construção do projeto terapêutico, para trabalhar na perspectiva do território, favorecer a corresponsabilização pelos casos e reverter, assim, a lógica do encaminhamento. Nesse ponto, é importante destacar a compreensão de Oliveira e Furlan (2008) para território, o qual vai além da delimitação geográfica e constitui-se historicamente por meio de relações socioeconômicas e culturais a serem conhecidas. O território é espaço de vivências, de identidades, trajetórias pessoais, coletivos organizados, movimentos sociais, de ação deliberada das pessoas, como também de relações sociais e redes de poder. 


\section{Colaboradoras}

Natália Freitas Dantas foi responsável pela concepção, delineamento e redação do artigo. Izabel Christina Friche Passos orientou a pesquisa e fez a revisão crítica do manuscrito. Não há conflito de interesses.

Resumen Este artículo presenta una investigación empírica con el objetivo de analizar la práctica del apoyo matricial en salud mental teniendo por base el estudio de caso dela experiencia de la ciudad de Belo Horizonte, Minas Gerais, Brasil, entre los años 2013-2014. Desde un enfoque cualitativo, fueron realizadas entrevistas individuales semiestructuradas con cinco psicólogos y dos representantes de la gestión, así como observación participante en las reuniones matriciales. Los datos fueron analizados utilizándose la metodología de análisis de contenido. En las reflexiones finales, está claro que el apoyo matricial viene transformando la relación de trabajo en las unidades básicas de salud en el sentido de la corresponsabilidad y el trabajo integrado entre los equipos. Sin embargo, todavía tenemos que avanzar hacia la construcción del plan terapéutico, ampliando las intervenciones más allá de la atención clínica individual, incluyendo la posibilidad de trabajar con grupos y en el territorio.

Palabras clave salud mental; atención primaria; apoyo matricial.

\section{Notas}

${ }^{1}$ Prefeitura de Belo Horizonte, Centro de Referência em Saúde Mental, Minas Gerais, Brasil. $<$ nataliafdantas@gmail.com>

Correspondência: Rua Romualdo Lopes Cançado, 834, apto. 101, bl. 03, Castelo, CEP 30840-460, Belo Horizonte, Minas Gerais, Brasil.

${ }^{2}$ Universidade Federal de Minas Gerais, Departamento de Psicologia, Belo Horizonte, Minas Gerais, Brasil.

<izabelfrichepassos@gmail.com>

${ }^{3}$ A Política Nacional de Atenção Básica considera os termos 'atenção básica' e 'atenção primária à saúde', nas atuais concepções, como termos equivalentes, daí a utilização indiscriminada de ambos neste artigo.

${ }^{4} \mathrm{O}$ Cersam equivale ao Caps III (Centro de Apoio Psicossocial). Belo Horizonte manteve o nome do serviço que já existia antes da criação da política nacional. 


\section{Referências}

AZEVEDO, Natalia S. Núcleos de apoio à saúde da família: o processo de implantação em Belo Horizonte, 2011. 108f. Dissertação (Mestrado em Psicologia) - Programa de Pós-Graduação em Psicologia, Pontifícia Universidade Católica, Belo Horizonte, 2011.

BACHETTI, Lívia S. Saúde mental e atenção básica à saúde: criação de uma rede de apoio matricial. Unopar Científica: Ciências Biológicas e da Saúde, Londrina, v. 15, n. 1, p. 13-19, 2013.

BARDIN, Laurence. Análise de conteúdo. Lisboa: Edições 70, 1995.

BARROS, Juliana O. et al. Estratégia do apoio matricial: a experiência de duas equipes do Núcleo de Apoio à Saúde da Família (Nasf) da cidade de São Paulo, Brasil. Ciência \& Saúde Coletiva, Rio de Janeiro, v. 20, n. 9, p. 2.847-2.856, 2015.

BELO HORIZONTE. Secretaria Municipal de Saúde. Relatório de gestão do SUS-BH: primeiro quadrimestre 2013. Belo Horizonte: Secretaria Municipal de Saúde, 2013. Disponível em: http:// portalpbh.pbh.gov.br/pbh/ecp/files.do?evento=download\&urlArqPlc=RDQA-1-quadrimestre-2013.pdf. Acesso em: 2 de fev. 2016.

BRASIL. Ministério da Saúde. Secretaria Executiva. Núcleo Técnico da Política Nacional de Humanização. HumanizaSUS: equipe de referência e AM. Brasília: Ministério da Saúde, 2004. (Série B. Textos Básicos de Saúde). Disponível em: <http://bvsms.saude.gov.br/bvs/ publicacoes/equipe_referencia.pdf $>$. Acesso em: 28 fev. 2016.

BRASIL. Ministério da Saúde. Secretaria de Atenção à Saúde. Coordenação Geral de Saúde Mental. Reforma psiquiátrica e politica de saúde mental no Brasil. Brasília: Opas, 2005. Disponível em: <http://bvsms.saude.gov.br/ bvs/publicacoes/Relatorio15_anos_Caracas. pdf $>$. Acesso em: 25 mar. 2016.

BRASIL. Portaria interministerial n. 154, de 24 de janeiro de 2008. Cria os Núcleos de Apoio à Saúde da Família-Nasf. Diário Oficial da União,
Brasília, 25 jan. 2008. Disponível em: <http:// bvsms.saude.gov.br/bvs/saudelegis/gm/2008/ prt0154_24_01_2008.html >. Acesso em: 2 abr. 2016.

BRASIL. Ministério da Saúde. Secretaria de Atenção à Saúde. Departamento de Atenção Básica. Diretrizes do Nasf: Núcleo de Apoio à Saúde da Família. Brasília: Ministério da Saúde, 2009 (Série B. Textos Básicos de Saúde) (Cadernos de Atenção Básica; n. 27).

BRASIL. Portaria n. 2.488, de 21 de outubro de 2011. Aprova a Política Nacional de Atenção Básica. Diário Oficial da União, Brasília, n. 204, seção 1, p. 48, 24 out. 201 la. Disponível em: <http://pesquisa.in.gov.br/imprensa/jsp/ visualiza/index.jsp?jornal $=1 \&$ pagina $=48 \&$ data $=24 / 10 / 2011>$. Acesso em: 1 mar. 2016 .

BRASIL. Portaria n. 3.088, de 23 de dezembro de 2011. Institui a Rede de Atenção Psicossocial para pessoas com sofrimento ou transtorno mental e com necessidades decorrentes do uso de crack, álcool e outras drogas, no âmbito do Sistema Único de Saúde. Diário Oficial da União, Brasília, n. 247, seção 1, p. 230-31, 23 dez. 2011b. Disponível em: <http://pesquisa.in.gov.br/imprensa/jsp/ visualiza/index.jsp?jornal $=1$ \&pagina $=230 \&$ data $=26 / 12 />.2011$. Acesso em: 10 mar. 2016.

BRASIL. Resolução n. 466, de 12 de dezembro de 2012. Diretrizes e normas regulamentadoras de pesquisas envolvendo seres humanos. Diário Oficial da União, Brasília, n. 12, seção 1, p. 59, 12 dez. 2012. Disponível em: <http://conselho. saude.gov.br/resolucoes/2012/Reso466.pdf>. Acesso em: 2 abr. 2016.

BRASIL. Ministério da Saúde. Secretaria de Atenção à Saúde. Departamento de Atenção Básica. Núcleo de Apoio à Saúde da Família. Brasília: Ministério da Saúde, 2014 (Cadernos de Atenção Básica, v. 39).

CAMPOS, Gastão W. S. O anti-Taylor: sobre a invenção de um método para cogovernar instituições de saúde produzindo liberdade e compromisso. Cadernos de Saúde Pública, Rio de Janeiro, v. 14, n. 4, p. 863-870, 1998. 
CAMPOS, Gastão W. S. Equipes de referência e apoio especializado matricial: um ensaio sobre a reorganização do trabalho em saúde. Ciência \& Saúde Coletiva, Rio de Janeiro, v. 4, n. 2, p. 393-403, 1999.

CAMPOS, Gastão W. S.; CUNHA, G. T. Apoio matricial e atenção primária em saúde. Saúde e Sociedade, São Paulo, v. 20, n. 4, p. 961-970, 2011.

CAMPOS, Gastão W. S.; DOMITTI, Ana C. Apoio matricial e equipe de referência: uma metodologia para gestão do trabalho interdisciplinar em saúde. Cadernos de Saúde Pública, Rio de Janeiro, v. 23, n. 3, p. 399-407, 2007.

CAMPOS, Rosana O.; GAMA, Carlos. Saúde mental na atenção básica. In: CAMPOS, Gastão W. S.; GUERRERO, André V. P. (orgs.). Manual de práticas em atenção básica: saúde ampliada e compartilhada. São Paulo: Hucitec, 2008. p. 210-236.

CHIZZOTTI, Antônio. Pesquisa em ciências humanas e sociais. 5. ed. Petrópolis: Vozes, 2011.

D'AMOUR, Danielle et al. A model and typology of collaboration between professionals in healthcare organizations. BMC Health Services Research [internet], Québec, n. 8, p. 1-14, 2008. Disponível em: <http://www.biomedcentral. com/1472-6963/8/188>. Acesso em: 2 fev. 2014.

DIMENSTEIN, Magda et al. Apoio matricial em unidades de saúde da família: experimentando inovações em saúde mental. Saúde e Sociedade. São Paulo, v. 18, n. 1, p. 63-74, 2009.

FERREIRA-NETO, João L. Psicologia, políticas públicas e o SUS. São Paulo: Escuta, 2011.

FIGUEIREDO, Mariana D.; CAMPOS, Rosana O. Saúde mental na atenção básica à saúde de Campinas, SP: uma rede ou um emaranhado? Ciência \& Saúde Coletiva, Rio de Janeiro, v. 14, n. 11, p. 129-138, 2009.

FITTIPALDI, Ana L. M.; ROMANO, Valéria F.; BARROS, Denise C. B. Nas entrelinhas do olhar: apoio matricial e os profissionais da Estratégia Saúde da Família. Saúde em Debate, Rio de Janeiro, v. 39, n. 104, p. 76-87, jan.-mar. 2015.
FURTADO, Juarez P. Equipes de referência: arranjo institucional para potencializar a colaboração entre disciplinas e profissões. Interface: Comunicação, Saúde e Educação, Botucatu, v. 11, n. 22, p. 239-255, maio-ago. 2007.

GOULART, Maria S. B. Equipe de saúde mental: a Torre de Babel da saúde pública. Cadernos de Psicologia, Belo Horizonte, v. 1, n. 2, p. 49-56, 1993.

LIMA, Maura; DIMENSTEIN, Magda. O apoio matricial em saúde mental: uma ferramenta apoiadora da atenção à crise. Interface: Comunicação, Saúde e Educação, Botucatu, v. 20, n. 58, p. 625-635, jul.-set. 2016.

MAY, Tim. Pesquisa social: questões, métodos e processos. 3. ed. Porto Alegre: Artmed, 2004.

MINAS GERAIS. Secretaria do Estado de Saúde. Linha guia de atenção em saúde mental. Belo Horizonte: Secretaria do Estado de Saúde, 2006.

MINAYO, Maria C. S. O desafio do conhecimento: pesquisa qualitativa em saúde. 11. ed. São Paulo: Hucitec, 2010.

OLIVEIRA, Gustavo N. Projeto terapêutico singular. In: CAMPOS, Gastão W. S.; GUERRERO, André V. P. (orgs.). Manual de práticas em atenção básica: saúde ampliada e compartilhada. São Paulo: Hucitec, 2008. p. 273-288.

OLIVEIRA, Gustavo N.; FURLAN, Paula G. Coprodução de projetos coletivos e diferentes 'olhares' sobre o território. In: CAMPOS, Gastão W. S.; GUERRERO, André V. P. (orgs.). Manual de práticas em atenção básica: saúde ampliada e compartilhada. São Paulo: Hucitec, 2008. p. 237-262.

SOUZA, Maria L. T.; TÓFOLI, Luís F. Apoio matricial na Estratégia Saúde da Família: atenção e cuidados psicossociais em saúde mental. Pesquisas e Práticas Psicossociais, São João del-Rei, v. 7, n. 2, jul.-dez. 2012.

Recebido em 02/05/2016. Aprovado em 23/05/2017. 